\title{
Identificação de estratégias utilizadas por professores de Educação Física para coibir o Bullying
}

\author{
Identification of strategies used by Physical Education teachers to prevent \\ the Bullying
}

Maxiano Dâmaso Martins ${ }^{1}$, Siomara Aparecida da Silva ${ }^{1}$, Daniel Barbosa Coelho ${ }^{1}$, Lenice Kappes Becker ${ }^{1}$, Emerson Cruz de Oliveira ${ }^{1 *}$

\begin{abstract}
O objetivo do trabalho foi investigar a percepção dos professores de Educação Física sobre a ocorrência de bullying nas escolas que atuam e elencar as ações utilizadas para prevenir o problema. Trata-se de um estudo qualitativo que utilizou como instrumento uma entrevista semiestruturada. Com base nos resultados é possível afirmar que as escolas não assumem o compromisso de planejar e aplicar estratégias que possam prevenir o fenômeno do bullying. Os dados também indicam que a formação inicial pode ter sido deficiente na preparação de professores para compreender e combater esse tipo de violência. Esperase que este estudo possa levar à reflexão não somente os professores envolvidos, mas também as instituições de ensino superior assim como as escolas para que o bullying seja corretamente estudado e combatido.

Palavras-chave: educação física, bullying, violência, escola.
\end{abstract}

ABSTRACT

The objective of this study was to investigate the perception of Physical Education teachers about the occurrence of bullying in the schools that act and to list the actions used to prevent the problem. A semistructured interview was the instrument used in this qualitative study. Based on the results, it is possible to affirm that schools are not committed to planning and applying strategies that can prevent the phenomenon of bullying. The data also indicate that initial training may have been deficient in preparing teachers to understand and combat such violence. It is hoped that this study may lead to reflection not only the teachers involved, but also higher education institutions as well as schools so that the bullying is properly studied and combated.

Keywords: physical education, bullying, violence, school.

\footnotetext{
${ }^{1}$ Universidade Federal de Ouro Preto, Ouro Preto, Brasil

* Autor correspondente: emerson@ufop.edu.br
} 


\section{INTRODUÇÃO}

A violência se tornou um problema de Saúde Pública, complexo, multidimensional e relacional, requerendo investimentos científicos e políticos para a ampliação e controle da problemática. Nota-se que o problema é cada vez mais crônico e recorrente e nem o ambiente escolar é preservado dos seus males (Marcolino et al., 2018).

Uma das formas de violência é o bullying. O bullying é uma prática de violência sistemática e intencional, dentro de uma relação desigual de poder entre alvo e autor (Olweus \& Limber, 2010). Manifesta-se, sob a forma de brincadeiras de mal gosto, apelidos, trotes, gozações e agressões físicas (Fante, 2005).

As origens do bullying são difíceis de se determinar, mas já foram encontradas associações entre a violência doméstica e o fenômeno. Alunas expostas à violência parental tornaram-se alvos/autoras de bullying na escola, enquanto os meninos apresentaram maior tendência de tornarem-se alvos, podendo também tornarem-se alvos/autores (Williams, 2009).

$\mathrm{Na}$ escola pode-se considerar alvo do bullying o (a) aluno (a) exposto (a) de forma repetida e durante algum tempo às ações negativas perpetradas por um ou mais colegas. Já os autores (as) geralmente são mais fortes fisicamente que seus alvos e podem se mostrar agressivos inclusive com os adultos, pois consideram sua agressividade como qualidade. As testemunhas são alunos (as) que não se envolvem diretamente em atos de bullying e geralmente se calam por medo de se tornarem alvos. E há ainda alvos/autores (as) que são os (as) alunos (as) que ora sofrem, ora praticam o bullying, portanto, esses (as) alunos (as) reproduzem os atos sofridos, em colegas inferiores.

Dessa forma a prevalência de ocorrência do fenômeno no interior das escolas já vem sendo estudada e os resultados de uma pesquisa realizada com uma amostra composta por 678 adolescentes, matriculados do $6^{\circ}$ ao $9^{\circ}$ ano escolar, em uma cidade brasileira, revelaram uma prevalência de vitimização de bullying que alcançou $29,5 \%$, sendo os meninos os principais alvos. Na mesma pesquisa também foi revelado que a prevalência de autores chegou a $8,4 \%$ dos estudantes pesquisados (Marcolino et al., 2018).

Considerando que o bullying determina um clima desfavorável à aprendizagem, no qual os envolvidos apresentam desempenhos insatisfatórios, problemas psicológicos como baixa autoestima e depressão, para as aulas de Educação Física o problema pode ser ainda maior, pois os alunos são levados a sair da sala de aula para espaços mais amplos como quadras e pátios e nesse trajeto podem ter contato com alunos de outras turmas favorecendo a ocorrência do bullying sendo alvos ou autores. Além disso, como as aulas de Educação Física acabam por evidenciar algumas capacidades ou dificuldades motoras, o cuidado dos professores deve ser ainda maior para não munir os autores com mais um motivo para atacar os seus alvos.

Assim, o objetivo do presente estudo é investigar a percepção dos professores de Educação Física em relação ao bullying e levantar ações adotadas pela escola e por esses professores para minimizar e prevenir o fenômeno.

\section{MÉTODO}

Trata-se de um estudo exploratóriodescritivo, que tem como objetivo registrar, analisar e interpretar os fatos sem manipulá-los, a fim de apreender significados, procedimentos e sentidos presentes nas práticas cotidianas desse grupo de professores.

\section{Participantes}

Participaram do estudo oito professores de Educação Física da cidade de Ouro Preto, Minas Gerais, Brasil. Informações adicionais sobre os professores estão na Tabela 1. Após o contato com as escolas informando sobre os objetivos da pesquisa e solicitação de assinatura das cartas de anuência, o projeto foi enviado ao Comitê de Ética em Pesquisa da UFOP com o registro CAAE 57185916.3.0000.5150. As coletas somente se iniciaram após a aprovação do projeto pelo referido comitê através do parecer de número: 1.907.199. Todos os professores assinaram um Termo de Consentimento Livre e Esclarecido. 
Tabela 1

Características dos professores

\begin{tabular}{ccccc}
\hline Professor & Idade & Sexo & Experiência & Formacão / Pós-graduacão \\
\hline A & 42 anos & Masculino & 11 anos & Licenciatura e Bacharelado em EF / PG \\
B & 49 anos & Feminino & 22 anos & Licenciatura e Bacharelado em EF \\
C & 31 anos & Masculino & 08 anos & Licenciatura em EF \\
D & 29 anos & Feminino & 07 anos & Licenciatura e Bacharelado em EF \\
E & 36 anos & Masculino & 10 anos & Licenciatura e Bacharelado em EF / PG \\
F & 34 anos & Masculino & 11 anos & Licenciatura em EF / PG \\
G & 49 anos & Feminino & 14 anos & Licenciatura em EF / PG \\
H & 41 anos & Masculino & 12 anos & Licenciatura e Bacharelado em EF / PG
\end{tabular}

Nota. EF = Educação Física; PG = Pós-Graduado

\section{Instrumentos e Procedimentos}

Foi aplicada uma entrevista semiestruturada com 10 questões abertas. O roteiro de entrevista passou por todas as etapas de montagem e checagem pertinente para esse instrumento. Em linhas gerais as perguntas versavam sobre as atitudes adotadas pelos professores frente a situações de bullying na escola; sobre os motivos apontados por eles como causadores de bullying; procuravam conhecer o nível de conhecimento dos professores sobre o bullying; identificar a ocorrência do fenômeno nas escolas pesquisadas e mais especificamente nas aulas de Educação Física; pesquisar se os professores se sentiam preparados para atuar diante da ocorrência do bullying; e por fim identificar as boas práticas que poderiam estar sendo empregadas pelas escolas ou por seus professores para combater esse tipo de violência. As entrevistas foram gravadas e o próprio roteiro já havia sido estruturado para permitir uma melhor categorização das respostas. Este instrumento é defendido como a melhor forma de interação para captação do que o outro pensa, sente, realiza ou pretende realizar a cerca de um tema específico (Günther, 2006).

\section{RESULTADOS}

Observou-se que, grande parte das respostas indicaram a realização de intervenções verbais frente a situações de bullying na escola. $O$ professor " $A$ " disse: "Eu me comporto de maneira que possa eliminar já estas brincadeiras logo no início, dentro de qualquer atividade do contexto escolar, porque se a gente percebe que está tendo uma brincadeira maliciosa, esta mesma pode se tornar lá na frente algo perigoso, tanto fisicamente, quanto moralmente, portanto já intervenho logo no início".

Aspectos físicos dos alvos foi o principal fator apontado como causador de bullying. A baixa na autoestima, o contexto social, a falta de respeito mútuo, a molecagem e a cultura familiar também foram citados. A professora " $D$ " disse: "uma das causas do bullying pode ser devido ao fato de que se espera que as escolas assumam o papel que deveria ser exercido pelos pais".

De modo geral, as respostas mostraram que os professores entendiam o bullying como agressões verbais, físicas e psicológicas, constrangimento e discriminação. Apenas a professora "B" avançou um pouco: "É uma expressão inglesa, associada a atitudes desrespeitosas para com os outros, como brincadeiras que oprimam, magoam e machucam". Em contrapartida, a professora "G" relatou de forma direta saber pouca coisa, justificando que não costuma pesquisar sobre o assunto.

Grande parte dos entrevistados citou o meio social, as mídias impressas, as televisivas e a internet como fontes de informações sobre o bullying. Apenas a professora " $\mathrm{D}$ " e o professor "E" relataram ter estudado sobre o bullying na graduação.

Sete dos professores afirmaram ter presenciado situações de bullying na escola, foram citados o uso de apelidos, agressões verbais e físicas, além de exclusão em decorrência da aparência física. Apenas o professor " $F$ " negou ter presenciado, afirmando: "não que eu tenha conhecimento".

Esses mesmos sete professores confirmaram a ocorrência do fenômeno nas aulas de Educação Física. Destes, o professor "A" e o professor "E" citaram a baixa habilidade técnica e motora, simplificadas como "técnica esportiva" como percursores destas brincadeiras durante as aulas, ocasionando conflitos e deboches, principalmente em modalidades coletivas. Obesidade e religião também foram fatores citados como causadores do bullying nas aulas de Educação Física. Apenas 
o professor "F" afirmou que durante suas aulas de Educação Física não ocorre o bullying.

Todos os entrevistados concordaram que as atitudes dos professores (principalmente a omissão) podem influenciar na ocorrência do bullying. A professora "B" afirmou que: "se o professor não intervém, ele se coloca do lado do opressor, acarretando uma 'normalidade' ao gesto ou prática do bullying". Já o professor "A", disse: "Com certeza! Quando você me fez esta pergunta, me veio em mente um professor que observei dando aula, a maneira com que ele interagia e se expressava com os alunos. Se o professor deu liberdade aos alunos, colocando apelidos, ao invés de chamar pelo nome, então ele já abre um leque para que esta prática se manifeste, pois, se ele que é o professor e está chamando por apelido, (E aí gordinho! E aí escurinho!), abre-se um leque para a turma reproduzir este tipo de atitude, neste momento ele deixa de ser o formador de cidadão, influenciando negativamente, propagando o fenômeno. Isso é questão de respeito, no qual o professor necessita saber lidar e agir com as diversidades que a escola engloba. Por isso o professor deve adotar uma postura no qual os alunos se espelhem"

Metade dos (as) professores (as) ("B", "D", "E" e "H") disseram que se sentem preparados para intervir nos casos de bullying. Entretanto, afirmaram que a formação acadêmica em nada contribuiu, mas sim a vivência. A professora " $D$ " disse: "Sim. Pela vivência do cotidiano, com vários tipos de alunos, ter trabalhado em várias escolas, de perfis diferentes e não pela formação acadêmica, este não é um tema muito abordado durante a formação acadêmica". Os outros professores disseram não se sentirem preparados. A professora "G" disse: "eficiente não, às vezes não sei como agir".

Os (as) professores (as) (“A”, "B", "D", "F”, "G", "H") disseram que as escolas não realizam intervenções de combate ao bullying. A resposta do professor "A" chama a atenção: "Não! De todas as escolas que trabalhei até hoje, não vi nenhuma escola fazendo isso! Em treze anos de profissão, estou sendo franco com você, pode me questionar isso a frente de qualquer diretor, nenhuma fez. "Os demais professores citaram palestras, murais e ações de conscientização, porém afirmaram que tudo ocorre de forma muito superficial, sem grande abrangência e consistência. O professor " $A$ " disse: "acho difícil realizar alguma abordagem aqui na escola, por que os professores são muito dispersos uns dos outros, então se eu idealizo, dificilmente alguém irá me ajudar, muitos acham que a intervenção é da disciplina, portanto cabido a mim".

Sobre as estratégias utilizadas para combater o bullying nas aulas de Educação Física, sete dos professores citaram as orientações verbais, uso de filmes, vídeos, oficinas e ações de conscientização no início do ano letivo. O professor "E" afirmou: "Sim. Sempre no início do ano deixo claro que não admito situações onde um aluno irá se sentir constrangido ou coagido". Apenas um professor afirmou não utilizar de nenhuma estratégia.

\section{DISCUSSÃO}

As intervenções verbais utilizadas pelos professores entrevistados como principal meio adotado frente as situações de bullying podem ser insuficientes no enfrentamento do problema. Já há na literatura discussões mais avançadas sobre a necessidade da realização de debates sobre bullying, criação de regras de inibição ao fenômeno, assim como a realização de uma melhor supervisão nos intervalos de aula e dos horários de entrada e saída da escola (Olweus, 1998).

Além dos motivos apontados pelos professores entrevistados como causadores do bullying, há outros mais difíceis de serem percebidos como problemas psicológicos, e ainda outros problemas que se iniciam na casa desses alunos, como a violência parental (Marcolino et al., 2018). A violência sofrida em casa que faz com que esses alunos acabem por aceitar a violência sofrida na escola como algo normal, especialmente no caso dos garotos, ou passem a reproduzir um tipo de violência que eles mesmos sofreram, em pessoas mais fracas que eles encontram nas escolas, acreditando que toda essa cultura de violência seja natural, pois foi iniciada em casa, ou seja eles sempre vivenciaram isso.

Acredita-se que a ampliação do entendimento do fenômeno deva começar nas instituições formadoras. As universidades devem realizar uma abordagem mais ampla e satisfatória sobre a 
violência escolar pois, são os professores que essas universidades estão formando que atuarão diretamente com a educação e, portanto, devem compreender profundamente este problema que é cada vez mais crônico e recorrente no âmbito escolar. Foi possível perceber no presente estudo que apenas os professores " $D$ " e "E" relataram ter ouvido falar de bullying durante a graduação, talvez por serem aqueles que terminaram mais recentemente seus cursos de graduação.

No presente estudo foi possível perceber que alguns professores relacionaram casos de bullying nas aulas de Educação Física com habilidades motoras e esportivas. A literatura aponta que o esporte precisa ser tratado pedagogicamente e de forma abrangente, considerando as suas outras dimensões (Finck, 2011). Assim o professor deve utilizar o esporte como ferramenta de ensino, possibilitando a participação de todos e estando atento a todos os acontecimentos durante a sua aula para imediatamente impedir que ainda mais motivos de bullying estejam disponíveis aos alunos.

Verificou-se que as escolas não adotam nenhuma prática preventiva. Neste sentido, a literatura vem evidenciando a relevância de incorporar ações que promovam diálogo, conscientização e a mobilização como meio buscar a minimização e controle do bullying e a importância de que essas ações sejam estruturadas e ininterruptas, englobando todo o segmento escolar, para que não se tornem ações isoladas e sem significado (Olweus, 1998).

Os professores entrevistados também não apresentaram nenhuma estratégia que mereça destaque no enfrentamento ao bullying e chamou atenção a fala do professor "A" que mostrou claramente a falta de unidade dos professores em relação a um projeto que um deles poderia idealizar. A angústia de caminhar sozinho ainda mais no enfrentamento de um fenômeno tão complexo pode ser a causa que impeça o surgimento de ações inovadoras nas escolas e mais especificamente nas aulas de Educação Física, por parte dos professores. O presente trabalho falhou em identificar as melhores estratégias de enfrentamento ao bullying em grande medida porque aparentemente $\mathrm{o}$ problema não vem sendo enfrentado e não porque os instrumentos e procedimentos da pesquisa foram inadequados.

Por fim, romper com a visão simplista de que bullying é algo inofensivo sem dúvida é o primeiro desafio para os educadores e para a sociedade como um todo. Estudos abrangendo maior números de professores e realizado em mais cidades necessitam ser feitos, sendo esta a maior limitação do presente estudo.

\section{CONCLUSÕES}

Evidenciou-se que a estratégia principal para coibir o bullying é a intervenção verbal, podendo ser válidas para interromper de imediato uma situação aguda. Entretanto, mais do que elas, é necessário também que a escola crie e proponha um trabalho pautado na importância da constituição dos princípios de tolerância, respeito, diversidade, valores e cultura. $\mathrm{O}$ trabalho multidisciplinar do corpo escolar juntamente a família, pode surgir também como uma ferramenta de combate, minimização e conscientização sobre bullying.

\section{Agradecimentos:}

Pró-Reitoria de Pesquisa e Pós-Graduação (PROPP) da Universidade Federal de Ouro Preto.

\section{Conflito de Interesses:}

Nada a declarar.

Financiamento:

Nada a declarar.

\section{REFERÊNCIAS}

Fante, C. (2005) Fenômeno Bullying: como prevenir a violência nas escolas e educar para a paz, $\left(2{ }^{\mathrm{a}}\right.$ ed. $)$ Campinas, Brasil: Versus Editora.

Finck, S. C. M. (2011) A Educação Física e o esporte na escola: cotidiano, saberes e formação, ( $2^{\mathrm{a}}$ ed) Curitiba, Brasil: Ibpex.

Günther, H. (2006). Pesquisa qualitativa versus pesquisa quantitativa: esta é a questão? Psicologia: Teoria e Pesquisa, 22 (2): 201-210. doi: 10.1590/S0102-37722006000200010.

Marcolino, E. C., Cavalcanti, A. L., Padilha, W. W. N., Miranda, F. A. N., \& Clementino, F. S. (2018). Bullying: prevalência e fatores associados à vitimização e à agressão no cotidiano escolar. Texto \& Contexto - Enfermagem, 27 (1), e5500016. doi: 10.1590/0104-07072018005500016. 
Olweus, D. \& Limber, S. P. (2010). Bullying in school: evaluation and dissemination of the Olweus Bullying prevention program. American Journal of Orthopsychiatry, $80 \quad(1): 124-34 . \quad$ doi: 10.1111/j.1939-0025.2010.01015.x.
Olweus, D. (1998) Conductas de acoso yamenaza entre escolares, ( ${ }^{\mathrm{a}}$ ed.) Madrid, Espanha: Morata.

Williams, L. C. A. (2009). Violência intrafamiliar e intimidação entre colegas no ensino fundamental. Cadernos de Pesquisa, 39 (138), 995-1018. doi: 10.1590/S0100-15742009000300015

Todo o conteúdo da revista Motricidade está licenciado sob a Creative Commons, exceto quando especificado em contrário e nos conteúdos retirados de outras fontes bibliográficas. 